\title{
Instructional Teaching Strategy can Boost an Activator of Students
}

\author{
Rahul Hajare* \\ National AIDS Research Institute, India
}

*Corresponding author: Rahul Hajare, ICMR NARI PDF Batch-2013-15 National AIDS Research Institute, Post-Doctoral Fellow 7th Batch 2013, Indian Council of Medical Research, PhD Scholar Batch-2007-12, Vinayaka Mission University, India, Email: rahulhajare@rediffmail.com

Submission: 酱 Dec 23, 2017; Published: 筒June 07, 2018

\begin{abstract}
A Teacher is a person who teaches in school rather than, especially helps others to shows knowledge, competence and value, playing a role of half mother and father. Concept mapping instructional approach as an activator of students' performance in the teaching and learning of excretion was investigated. The quasi experimental design was employed. Purposive sampling technique was used to select three intact biology classes of Senior High School 2 students with a total sample size of 108. The two main instruments used for data collection were General Knowledge in Biology Performance Test (GKBPT) and Students' Performance Test in Excretion (SPTE) with K-R 20 reliability coefficient of 0.812 and 0.866 respectively. Point Bi-serial Correlation, Wilcoxon Signed Rank test, effect size, chi-square and Kruskal-Wallis $\mathrm{H}$ test were employed to analyse the quantitative data collected using the students' achievement scores. The study showed that the effect size of the students' performance in the concept mapping of the post-test scores was better than that of the pre-test scores. The instructional approach did not only improve students' achievement in the biology course but also helped the students to retain the concept learned for longer period. Based on the result, recommendations have been made.

Keywords: Concept mapping; Effect size; Excretion; Senior high school
\end{abstract}

\section{Introduction}

Biology is a natural world through observation. Considering it is fundamental characteristics and importance, Biology is today a standard subject of instruction at all levels of our educational systems, from pre-primary to tertiary. Essentially it could be considered the only core science subject at Senior Secondary School Certificate Examination (SSSCE), whose study is very relevant to man's successful living. Biology occupies a unique position in the school curriculum, and is central to many science related disciplines such as Medicine, pharmacy, agriculture, nursing and biochemistry. The knowledge of Biology, chemistry and physics which have been crystallised into concepts, empirical laws and theories form the basis of our material comfort. The knowledge of Biology contributes to scientific literacy so that people can understand the world around them and enable them to make informed choices about their health care, their environment and the society in which they live. As we entered the 21st century and expected better health for all; abundant food for all; better knowledge of man, animals and plants; and less polluted environments with Sulphur (IV) Oxide and radioactive substances, there is the need to effectively teach and learn Biology to meet these challenges. The sensitive position Biology plays in medical sciences, environmental sciences and other related disciplines has informed several efforts geared toward studying biology at a secondary level of education in many parts of the world including India. Hence, it is one of the science subjects one must pass so as to qualify to pursue some science courses at the tertiary level of education. For these reasons, the biology Teaching Syllabus (Ministry of Human Resource and Development High Education, India) for Senior High School (SHS) in India, aims at assisting the learner to appreciate the diversity of living things; understand the structure and functions of living things; develop scientific approach to solving personal and societal (environmental, economic and health) problems, develop practical skills required to work with scientific equipment, biological materials and living things; collect, analyse and interpret biological data; and also present data graphically. It also focuses on making biology students aware of the existence of interrelationships between biology and other scientific disciplines; appreciate and understand the interrelationships between organisms and themselves and with the environment, and sustain their interest in studying biology. Despite the importance of the knowledge of biology for socio-economic development of a country, it has been reported that performance in biology at SHS level has been poor in most parts of the outskirt of India and there is no exception. Biology is popular among hard worker students, yet their performance in it at Secondary School level is low. The situation is not different in international school in India. For instance, the Ministry of Education of India in early 2005 indicated that there is a decline in the performance of students in biology. 
Reported in their study titled "an investigation into weaknesses exhibited by Senior High School biology Students. Many students who sit the SSSCE in the sciences, specifically, biology, do not perform as expected. They further lamented that this has been a constant source of worry to parents, teachers, educationists and those who have the advancement of science education in India at heart. Again, it was indicated in the work that the performance in biology has also not seen any significant difference over the years as evidenced by the general comments in the West African Examinations Council (WAEC) Chief Examiners' reports for July/ Aug. The researchers believe that students' inability to deeply conceptualise the individual topics treated in biology could account for their woeful performance in the biology papers in general. For example, studies consistently showed that students have problems in understanding key topics of biology such as internal organs, organ systems and processes of their own bodies [1]. Evaluated young children's awareness of biological transformations associated with eating and breathing and showed that young children seldom refer to biological transformation. Results from an international study indicated that about 15 year-old students' (from 11 different countries) understanding of different organ systems showed that the generally best known organs belong to the digestive system, gastrointestinal Antacid the gaseous exchange system and the skeletal system. It was evidenced in the study conducted by students had better knowledge of their internal organs but most of them had little understanding of their organ system. Reiterated that students had greater difficulties in understanding the excretory systems than the digestive. The students' difficulties in understanding excretory systems are mainly caused by ineffective learning or poor teaching in the classroom. Lawson furthered that when appropriate teaching and learning approaches are not employed in the classroom, students turn to develop certain misconceptions about the topic learned, particularly those that are concerned with more complex or abstract phenomena such as cell division, ultra filtration in nephrons and the mechanism of circulation, children are less likely to come into immediate and direct contact with them in daily life, and so have little chance to develop their own 'naive' explanations. Emphasised that teacher-centred teaching approach, inadequate mastery of subject matter by the teachers and inadequate teaching and learning resources are among other contributing factors that impede students' conception and performance in certain topics in biology. They emphasised that the teaching approach employed by a teacher is one of the most important explanations of poor performance in science subjects. One teaching approach which has been identified to be dominant in Secondary School level is lecture method [2]. It is teacher-centred teaching approach where a teacher presents information to students in a lecture and students complete assignments out of class and later take an examination to demonstrate their degree of understanding and retention of the subject matter. The lecture method which is predominant in our classrooms does not stimulate students' thinking. Opined that teaching and learning is an attempt to help someone acquire or change some knowledge, skill or attitude. Further argued that teaching and learning is a process where one person, the teacher intentionally passes information to another person, the learner. Hence, the goal of teaching is to bring about desirable learning in students. In this process, the learner is expected to receive information, understand it and use it later when the need arises. For effective teaching and learning to occur, the teacher must use an effective approach of conveying the information to the learner [3]. He further noted that the way a teacher teaches is important in that with the right methods and techniques, students can grasp concepts and ideas while poor methods and techniques frustrate students and minimize their chances of success.

\section{Conclusion}

The instructional strategies that have been identified to aid students' conception and performance are concept mapping and co-operative learning, which are practically non-existent in the situation where the researchers conducted the study.

\section{Acknowledgment}

This study has been guided under the guidance of Renowned Laboratory Scientist Respected Dr. Ramesh Paranjape, Retd. Director and Scientist ' $G$ ' National AIDS Research Institute India. I express my sincere gratitude towards Respected Sir for motivation and being great knowledge source for this work.

\section{References}

1. Rahul H (2017) Understanding academic and educational problems fit for purpose in the contributing to attention and learning difficulties in our children. Glob J Oto 11(5): 555-822.

2. Rahul H (2017) Live and let live: Acceptance of learning disability of people living with Co-educational pharmaceutical institute selffinanced and privately managed remote areas in india where stigma and discrimination persist. Current Opinions in Neurological Science 1(6): 311-313.

3. Rahul H (2017) Early rising may be linked to mental health issues in institute of pharmaceutical science an observational study draws inference from a legal to cultural principles through independent variables. Biomed J Sci \& Tech Res 1(1): 1-2. 
Creative Commons Attribution 4.0 International License

For possible submissions Click Here
PRM Imanen

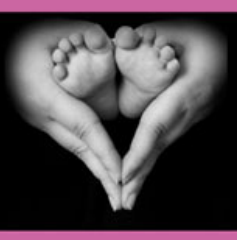

Perceptions in Reproductive Medicine

\section{Benefits of Publishing with us}

- High-level peer review and editorial services

- Freely accessible online immediately upon publication

- Authors retain the copyright to their work

- Licensing it under a Creative Commons license

- Visibility through different online platforms 